\title{
Práticas discursivas no cuidado com os corpos em Almodóvar: laços familiares atuais instituídos pelo sujeito feminino
}

\author{
Discursive practices in body care in Almodóvar: current family ties imposed by the female \\ subject
}

\begin{abstract}
Nadea Regina Gaspar
Doutorado em Linguística e Língua Portuguesa pela UNESP. Professora do Programa de Pós-graduação em Ciência, Tecnologia e Sociedade e Professor adjunto do Departamento de Ciência da Informação da UFSCar. E-mail: nagaspar@terra.com.br

Eliana Mantovani Malvestio Graduação em Biblioteconomia e Ciência da Informação UFSCar E-mail: elianamalvestio@yahoo.com.br
\end{abstract}

\begin{abstract}
"O que me interessa é o ser humano, que é a cada vez único e que compreende em si todos esses elementos de masculino e feminino" (Pedro Almodóvar).
\end{abstract}

\section{Resumo}

Esta pesquisa tem por objetivo compreender a função do sujeito "feminino" nos filmes de Pedro Almodóvar. Recorremos para tanto, à teoria da análise do discurso de Michel Foucault (1995), em sua compreensão sobre "enunciado" e "formações discursivas". Este texto expõe aspectos desse percurso teórico para lidar com as questões que se nos apresentavam inicialmente: o que eleger na análise de um acervo fílmico, uma vez que, em quase todos os textos, no caso, desse diretor, as mulheres se fazem presentes? Como selecionar e relacionar nas análises as cenas e/ou as sequências fílmicas, neste universo de imagens em movimento? No sentido exposto, debruçamo-nos inicialmente frente a dezesseis (16) dos dezoito filmes de Almodóvar, e desses, delimitamos três (3) para esta análise: "Tudo sobre minha mãe" (1999), "Fale com ela" (2002) e "Volver" (2006). Como resultado, foi observado à presença constante de um enunciado que permeou o trabalho: "a prática dos cuidados realizados por sujeitos femininos aos seus familiares”. Este enunciado, embora pareça comum, nos filmes desse diretor surpreende, pois ele está vinculado a formação de um discurso bastante atual: "as novas constituições familiares derivadas das práticas do cuidado feminino".

Palavras-chave: Análise do discurso; análise fílmica; Michel Foucault; Almodóvar.

\begin{abstract}
This research aims to understand the function of the subject "women" in the films of Pedro Almodóvar. For that we recourse to the theory of discourse analysis of Michel Foucault (1995), in its understanding of "statement" and "discursive formation." This text presents aspects of this theoretical approach to deal with the issues presented initially: what to select for analysis in a film archive, since, in almost all texts, in this case, of that director, women are present? How to select and relate the scenes and/or film sequences in the analysis this universe of images in movement? In the above sense, we have looked at the first sixteen (16) out of the eighteen films of Almodóvar, and of those, separated three (3) for this analysis: "All About My Mother" (1999), "Talk to her" (2002) and "Volver" (2006). As a result, we observed the constant presence of a statement that permeated the work: "the practice of care performed by female subjects to their family members." This statement, although it seems common in films of this director, are surprising because he is linked to formation of a very contemporary discourse: "the new family constitutions derived from the practices of female care."
\end{abstract}

Keywords: Discourse analysis, film analysis, Michel Foucault, Almodóvar.

InCID: R. Ci. Inf. e Doc., Ribeirão Preto, v. 2, n. 2, p. 54-66, jul./dez. 2011. 


\section{Introdução}

A pesquisa que segue descreve parte de um projeto de pesquisa, e busca apresentar a figura da mulher, ou antes, a função do sujeito "feminino", nos filmes de Pedro Almodóvar. Recorremos para tanto, inicialmente, à teoria da análise do discurso de Michel Foucault (1995) em sua compressão sobre "enunciado" e "formações discursivas". Este texto expõe aspectos desse nosso percurso teórico para lidar com as questões que se nos apresentavam inicialmente: o que eleger na análise de um acervo fílmico, uma vez que, em quase todos os textos, no caso desse diretor, as mulheres se fazem presentes? Como selecionar e relacionar nas análises as cenas e/ou as sequências fílmicas neste universo de imagens em movimento?

Foucault (1995, p.134) diz que a análise do discurso revela como os diferentes textos se "remetem uns aos outros, organizam-se em uma figura única, entram em convergência com instituições e práticas, e carregam significações que podem ser comuns a toda uma época”. Tomando-se isso como pressuposto, os sentidos produzidos nas análises e advindos da circulação de enunciados discursivos estão contidos na memória da humanidade, e estão ligados, inicialmente, por uma interdiscursividade. Ou seja, um livro, um artigo de revista, uma música, um filme, não têm uma fronteira definida e um fim em si mesmos, no que diz respeito ao discurso; eles estão imersos em um sistema que os remetem a outros textos. Isto é possível de ser apreendido, por esta teoria, quando se encontra, por meio do trabalho de leitura e análise, “o enunciado discursivo” (FOUCAULT, 1995, 87-152).

No sentido exposto, debruçamo-nos inicialmente, frente a dezesseis (16) dos dezoito filmes de Almodóvar, e buscamos encontrar o enunciado discursivo, tal como o compreende Foucault (1995), por meio do nosso olhar atento aos: "sujeitos", fixando-nos nos femininos, "série", “materialidade”, “campos que se associam”. Considerando, porém, que precisávamos fazer recorte, próprio a todo trabalho de pesquisa, delimitamos três (3) filmes de Almodóvar para a análise: "Tudo sobre minha mãe" (1999), "Fale com ela" (2002) e "Volver" (2006).

Nos pronunciamentos dos sujeitos femininos, a cada vez que eles se apresentavam nos filmes, a análise foi-nos revelando que começava a surgir uma configuração em que era possível associar a figura dos sujeitos femininos com a dos "cuidados" que esses despendiam para com outros sujeitos, no caso, personagens fílmicos.

Foi deste modo que conseguimos observar a presença constante de um enunciado que permeará todo nosso trabalho: "a prática dos cuidados realizados por sujeitos femininos 
aos seus familiares". Esse enunciado, advindo desses filmes, desse diretor, tornou-se o "pano de fundo" ou a "linha temática" a este trabalho.

Encontrar, por meio de associações enunciativas discursivas fílmicas que demonstram as mulheres "cuidando dos familiares" nos fez perceber que a "família" que Almodóvar nos apresenta é bastante diferenciada da que conhecemos e aprendemos "desde sempre" no nosso meio social (escola, instituições religiosas, etc). Isso porque ele apresenta e antecede em seus filmes, ou no arquivo discursivo fílmico que nos propomos a analisar, uma configuração bastante atual sobre o modelo de "família". Ou seja, uma "formação" de um "discurso" sobre as constituições familiares atuais, pautada em princípios diferenciados, decorrentes do cuidado e do afeto.

A seguir, então, apresentaremos parte deste percurso teórico, tal como propostos por Foucault (1995), em análises dos filmes de Pedro Almodóvar, buscando demonstrar o nosso encontro com esse enunciado e essa formação discursiva. Momento de explanar aspectos dos conceitos e como eles se embatem; momento em que nossas descobertas superaram as expectativas iniciais e nos trouxeram revelações inesperadas - "o descaminho daquele que conhece", conforme fala Foucault (1984) na introdução de "O uso dos prazeres". O que gera e gesta o real sentido ao conhecimento.

Comecemos por Foucault.

\section{Apontamentos sobre a análise do discurso em Foucault}

A arqueologia, ou melhor, a arqueogenealogia, como nos explica Inês Lacerda Araújo (2008), constitui-se pela filosofia crítica do sujeito de Michel Foucault - por sua potencialidade de "localizar ordens ou configurações de saber e delas fazer uma experiência crítica, uma análise" (ARAÚJO, 2008, p. 96), dirigindo-se "ao espaço geral do saber [...] e ao modo de ser das coisas que aí aparecem" (FOUCAULT, 2000, p. 12).

Segundo Fischer (2001), o discurso não é apenas um conjunto de signos como comumente aprendemos, pois os significantes (observados por meio de palavras, imagens, sons, etc.) carregam significados, em sua maioria não visível, e carecem de análises neste sentido. Os signos, assim, não são desprezados nas análises discursivas foucaultianas, pois devem ser operados no movimento da relação analítica, se se considerar, porém, a relação

InCID: R. Ci. Inf. e Doc., Ribeirão Preto, v. 2, n. 2, p. 54-66, jul./dez. 2011. 
entre eles e o enunciado discursivo. Além de que, o enunciado discursivo encontra-se em um grupo de textos, formando um dado discurso, gerando um "percurso temático" (GUILHAUMOU, J.; MALDIDIER, D., 1994, p. 163-183).

Para Foucault (1995), deste modo, o discurso põe em funcionamento os enunciados, bem como a relação entre eles, presentes nas formações discursivas. É por meio da análise dos discursos que se revelam os engendramentos das práticas ocorridas nos meios sociais. Sendo assim, os pronunciamentos - feitos por sujeitos do discurso - em dada época, lugar, meio social, são constitutivos dos enunciados e carregam características históricas.

As análises enunciativas discursivas revelam para o analista, deste modo, de que modo os discursos se estabilizam em determinadas formações discursivas (discursos religiosos, científicos, familiares, etc.), ou de que modo os discursos "migram" de uma dada formação para outra. Isso porque, em um momento histórico, há discursos que podem ser enunciados e outros que são apagados, silenciados. Isso justifica o aparecimento e também a proibição de determinados enunciados como sendo verdadeiros, em detrimento de outros que passam a ser legitimados, revelando a posição e mecanismos de poderes e saberes que os indivíduos ocupam nos enunciados, enquanto sujeitos de discursos.

Analisar discursos, assim, significa buscar compreender a maneira como as verdades são pronunciadas, ou porque algumas verdades são omitidas, interditadas, já que "a produção do discurso é controlada, selecionada, organizada e redistribuída por procedimentos que visam a determinar aquilo que pode e deve ser dito em um certo momento histórico" (GREGOLIN, on line).

"O que pode e deve ser dito" em dado "momento histórico" advém de pronunciamentos (verbais e não verbais) que são enunciados por sujeitos, e esses desempenham funções e posições na "ordem dos discursos" (FOUCAULT, 1999a). Na eleição dos sujeitos nas análises priorizam-se aqueles que se encontram aptos para tal função, e devido a isso é que Foucault (1995) distingue sujeito e autoria, pois para ele o sujeito não é idêntico ao autor. O autor, segundo Foucault (1999b, p. 26), é o "princípio de agrupamento do discurso, unidade e origem de suas significações, foco de sua coerência". Já, o sujeito do enunciado é concebido por esse autor (1995, p. 109) como: "um lugar determinado e vazio que pode ser efetivamente ocupado por indivíduos diferentes [...]. Descrever uma formulação enquanto enunciado [...] [consiste] em determinar qual é a posição que pode e deve ocupar todo indivíduo para ser sujeito". 
Deste modo, conforme diz Gaspar (2004), o sujeito enunciador se destaca pelo lugar e posição que ocupa no funcionamento discursivo; um lugar, pois seu pronunciamento advém de diversas práticas estabelecidas institucionalmente; e a posição, uma vez que, seu saber é oriundo de um domínio próprio (de vivências) do sujeito que enuncia. Gaspar (2004, p. 276), que traz os procedimentos foucaultianos da análise do discurso para o ambiente cinematográfico, esclarece que, "considerando o filme, é possível observar a existência de vários sujeitos enunciadores [...]: personagens, roteiristas, fotógrafos, tradutores, músicos, figurinistas, pessoas que trabalham com a mixagem do som, editores de imagem". De fato, existem filmes em que a fotografia é tão presente que o sujeito enunciador, nesse caso, seria o fotógrafo ou o profissional que manuseia a câmera; em outros, a música é tão marcante, que talvez o sujeito enunciador pudesse ser o músico ou a música. Isso indica que, se os sujeitos assumem posições diferenciadas no funcionamento discursivo, o autor - no caso do filme, o diretor - assume a posição de "princípio de agrupamento dos discursos", pronunciados pelos vários sujeitos enunciadores.

Diante do breve exposto teórico, adentremos, agora, nas práticas discursivas sobre os sujeitos femininos, nos filmes de Almodóvar.

\section{Práticas discursivas femininas sobre o “cuidar” da família em Almodóvar}

Em cada um dos filmes analisados de Almodóvar, há uma família biológica central composta pelas figuras do pai, da mãe, do filho ou filha, ainda que, muitas vezes, alguns desses sujeitos são apresentados apenas pelo nome. Também em cada filme há um sujeito curador de outro, e que é central: Manuela, em "Tudo sobre minha mãe" (1999); Benigno, em "Fale com ela" (2002); e Irene, em "Volver" (2006). Traçando relações discursivas entre eles nota-se, evidentemente, o zelo empreendido a outras personagens, o cuidado especial que apresentam para com algumas delas, e as suas 'atuações' como mães.

Ainda que, a primeira vista, pareça inapropriado colocar um homem como mãe, caso de Benigno, sua conduta ao longo da narrativa demonstra que ele se mostra como um ser humano que cuida como se fora uma mãe protetora, ou seja, ele conversa com todos, se preocupa, se doa, e demonstra: "atitudes de mãe". Julgamos, por isso, que ele também se insere na análise juntamente àqueles que têm a "aura da feminilidade", tendo em vista o seu comportamento na função que ocupa (a de enfermeiro) e o modo delicado e atencioso como 
cuida de pessoas, como veremos adiante. Sendo assim, e tendo esse caráter materno, o colocamos em paridade com as mães Manuela e Irene.

Vejamos como ocorre esse movimento enunciativo em cada um desses filmes de Almodóvar.

Em “Tudo sobre minha mãe” (1999), a família biológica "original” é constituída pelos sujeitos: Esteban, que era um pai ausente e machista e se transforma em uma travesti (Lola); Manuela, uma mãe que cuida de seu filho; e Esteban, um rapaz que morre ao completar dezoito anos. No decorrer da narrativa percebe-se que o pai, mesmo ao assumir a posição de travesti, mantém sua postura machista, afastando Manuela, que foge com o menino Esteban em seu ventre.

Com a morte do filho homônimo ao nome do pai, Manuela o procura para avisá-lo do ocorrido, trajetória em que ela se adequa a novos membros que passam a ser sua família, agora não consanguínea. Ocorre que, na relação entre esses sujeitos, o que se observa no movimento discursivo, é que, por um incidente, Lola engravida (e abandona) Irmã Rosa, que não passa bem durante a sua gravidez, necessitando de cuidados. Quem a ajuda, como se fosse a sua mãe, é Manuela, como pode ser visto na figura 5.

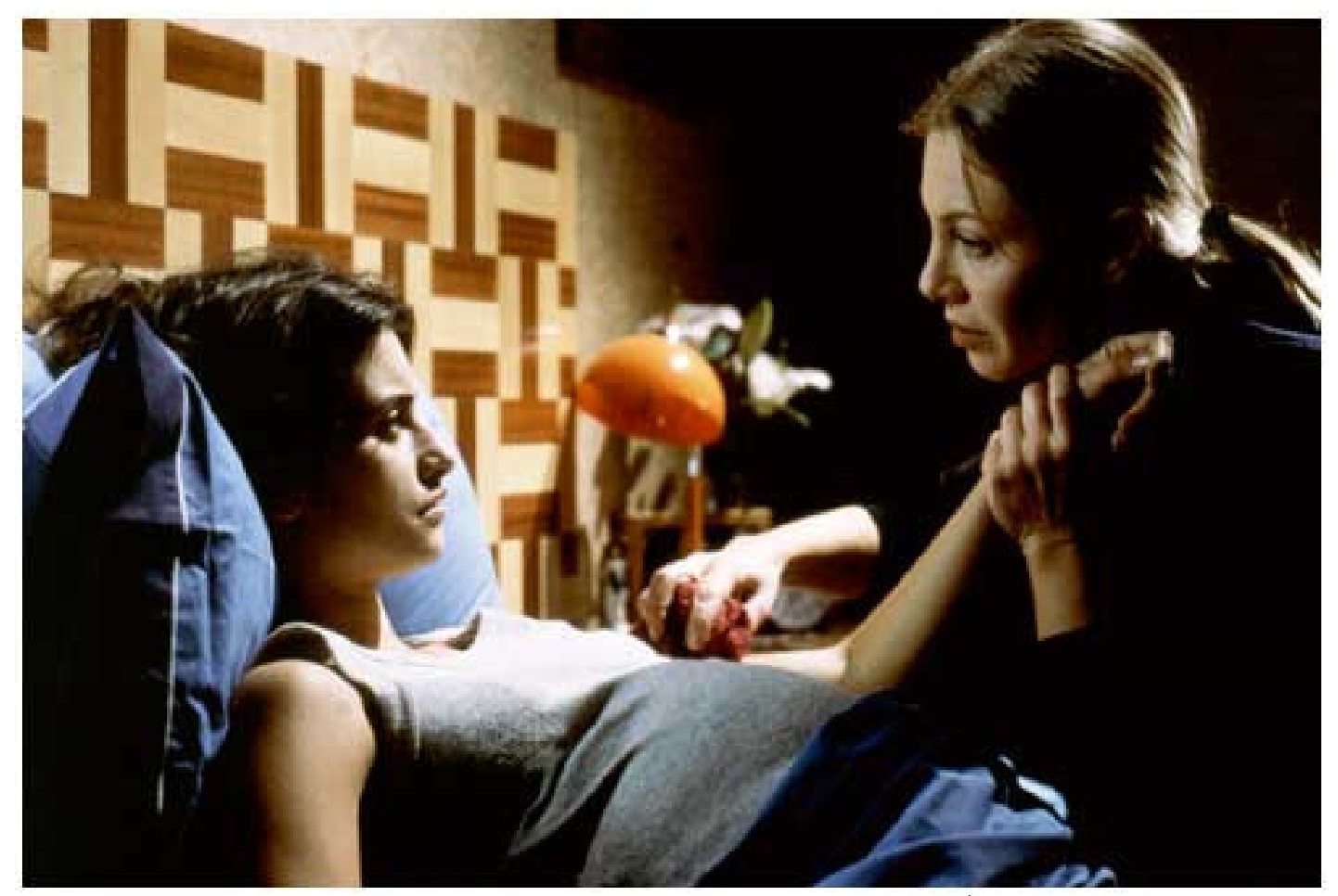

Figura 1 - Prática dos cuidados em "Tudo sobre minha mãe" (ALMODÓVAR, 1999)

Fonte: blog livre "Repertório cultural”: (http://repertoriocultural.blogspot.com/2007_02_01_archive.html) 
Nesta trama, Manuela parece cuidar de todos os que a encontram. Além de ter cuidado de seu filho amado Esteban, cuida também agora de outros membros de sua família não biológica (Huma Rojo e Nina Cruz), e abdica de seu trabalho para prestar cuidados a quem seria seu "novo filho" não consanguíneio, advindo da relação de Lola (Esteban) e Irmã Rosa.

Neste breve relato desse filme, sobre as (des)construções e (re)construções familiares, em que os membros vão assumindo identidades, observamos que de modo algum as famílias interagem unicamente entre si, mas se afinam principalmente com pessoas que se encontram entorno delas, como pessoas de outras famílias, os vizinhos e amigos. Este modelo familiar atual, que começa a ser discursivisado nos textos, no caso, em filme, parece ter suas origens em um passado.

Ariès (1981, p. 11) explica que, no passado, embora o ambiente familiar fosse criado para proteger os seus membros,

[...] o sentimento entre os cônjuges, entre os pais e os filhos, não era necessário à existência nem ao equilíbrio da família: se existisse, tanto melhor. As trocas afetivas e as comunicações sociais eram realizadas, portanto, fora das famílias, num 'meio' muito denso e quente, composto de vizinhos, amigos, amos e criados, crianças e velhos, mulheres e homens, em que a inclinação se podia manifestar mais livremente. As famílias conjugais se diluíam nesse meio. Os historiadores franceses chamariam hoje de 'sociabilidade' essa propensão das comunidades tradicionais aos encontros, às visitas, às festas.

Parece-nos que Almodóvar recria, sob parâmetros atuais de conduta, este ambiente familiar de outrora. Isso se confirma, no movimento da série enunciativa discursiva, em mais um dos filmes desse autor.

Em "Fale com ela" (2002), há duas famílias biológicas: a de Benigno, um enfermeiro, e a de Alicia, uma dançarina. Na família de Benigno, sua mãe foi cuidada por ele até sua morte, mas isso aparece em breves relatos orais ou em cenas de "flash back", como quando ele diz: "Quando comecei a tomar conta dela era quase um menino [...] Nunca saí do lado dela" (FALE..., 2002). Seu pai, ausente, tem rápida menção no filme, dando-nos a compreender sobre seu afastamento da família, e demonstrando, com isso, a pouca representatividade que teve na educação do filho. O doutor Roncero, função ocupada pelo sujeito que é pai de Alicia, se faz presente na narrativa, mas a identidade da mãe da moça passa despercebida já que não se sabe seu nome, ainda que ela seja rapidamente mencionada em uma conversa entre Benigno e Alicia que relata sua morte ocorrida há muito tempo. Nesse filme, Benigno, o enfermeiro, oferece constantes cuidados à Alicia, que se encontra em coma 
no hospital em que ele trabalha, como é demonstrado abaixo na figura 6 , além de que, ele a ama há muitos anos.

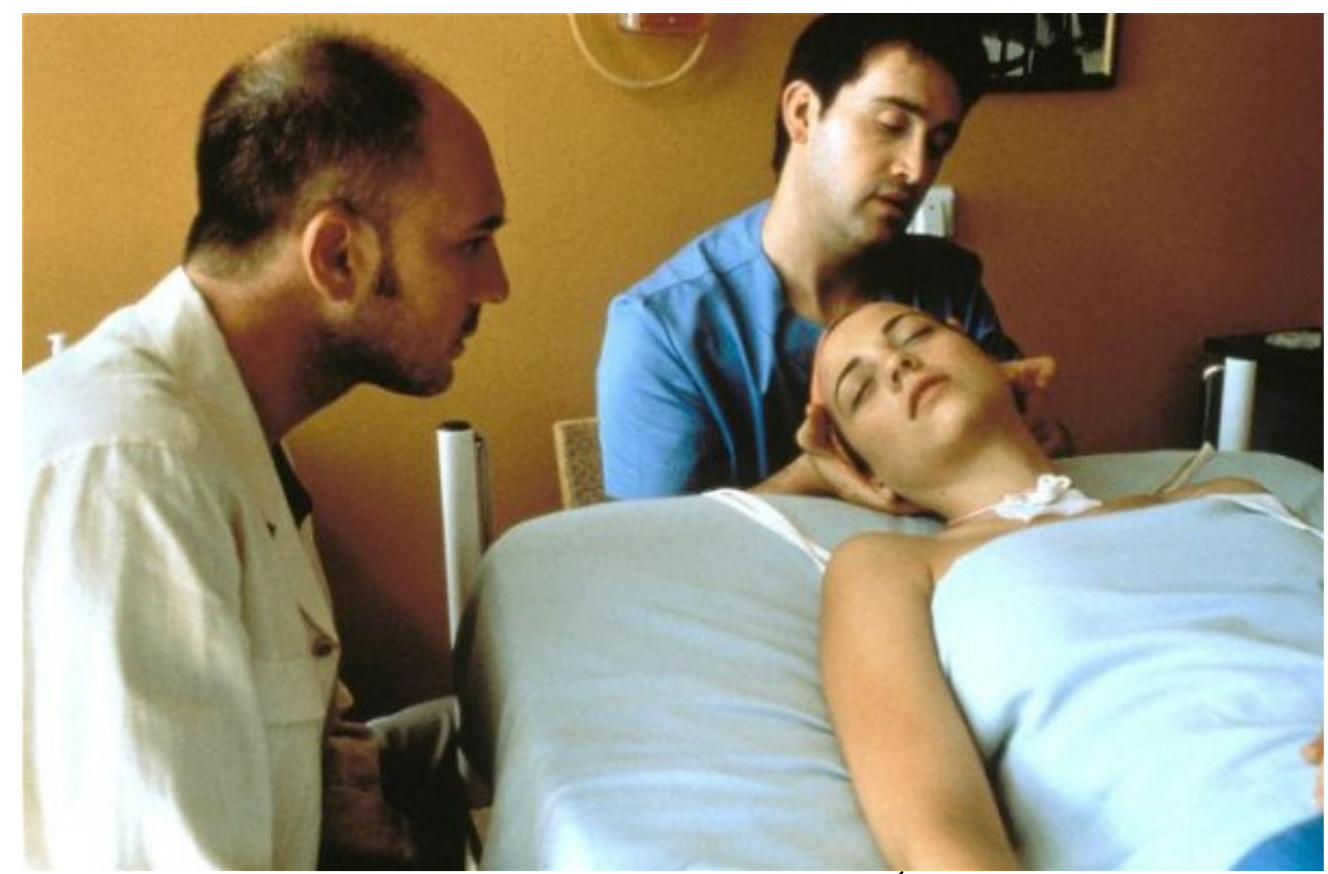

Figura 2 - Prática dos cuidados em "Fale com ela" (ALMODÓVAR, 2002)

Fonte site livre "Trilha filmes": (http://www.trilhafilmes.com.br/noticia.php?id=01591)

$\mathrm{Na}$ trama da narrativa fílmica, e focando o que nos interessa no texto, percebe-se, novamente, que novos laços de família vão surgindo: Benigno, que engravida Alícia ainda em coma, é preso, e se mata na cadeia, acreditando, que com esse ato, conseguiria produzir um "estado de coma em si mesmo" para "estar junto com ela". Contudo, ele tinha um amigo Marco Zuloaga, e esse conheceu Alícia, que após o aborto, "renasce” para uma nova vida, apaixonando-se por Marco. Por sua vez, Katerina, professora de balé de Alicia, assume a função de mãe da dançarina. Ou seja, aqui vemos que "os cuidados" de sujeitos com características femininas para com os sujeitos que precisam ser cuidados, instigam o nascimento de novos modelos familiares. Benigno, também estende seus cuidados a outros sujeitos (na acolhida a Marco, quando se conhecem no hospital e numa visita breve ao quarto de Lydia, a toureira, também em estado de coma). Mantém-se preocupado, mesmo estando na prisão, quando ao receber a visita de Marco molhado pelo dia chuvoso, indica-lhe um copo de leite quente com mel, para ele não se resfriar, como se fosse mesmo uma "mãe" aconselhando seu filho.

Novamente neste filme, assim como em "Tudo sobre minha mãe" (1999), o que se observa são sujeitos que desconstroem suas famílias, previamente estruturadas por modelos tradicionais, para reconstruí-las em novas formas de vivência familiares. Sujeitos que se unem 
agora, por laços não somente consanguíneos, mas firmando-se sob o amparo de cuidados: doados e recebidos.

Vejamos em mais um dos filmes de Almodóvar, na cadência do movimento "serial", observando os "campos de coexistências" que gestam o enunciado discursivo, e que retratam "sujeitos", em que se pode vê-los, ouvi-los e lê-los nas "materialidades" verbais e não verbais, situações que demonstram os "cuidados familiares".

Em "Volver" (2006), temos na família central três gerações matrilineares - a avó Irene, as filhas Raimunda e Sole, e a neta Paula, filha de Raimunda. A figura do pai aparece marginalizada, tanto quanto nos outros dois filmes analisados. Nessa família, a mesma história se repete nas duas gerações: pais que abusam de suas filhas. O marido de Irene, cujo nome sequer fora mencionado, abusa de sua filha Raimunda e a engravida, Paula é fruto deste incesto. Paula, por sua vez, é também vítima de abuso de seu pai não-biológico, Paco, marido de Raimunda. Desta vez, o corruptor é morto e não concretiza o ato do abuso contra a jovem. Parece-nos que Irene, exerce amplamente a posição de mãe. Preocupa-se e cuida de suas filhas Sole e Raimunda, cuida durante alguns anos de tia Paula, dá conselhos à sua neta Paula da importância e de como se aproximar de sua mãe. Além de que, ela devota-se, também, à Agustina, a filha não consanguínea, numa certa compensação por ter causado a morte de sua mãe, como se vê na figura 3 , que segue. 


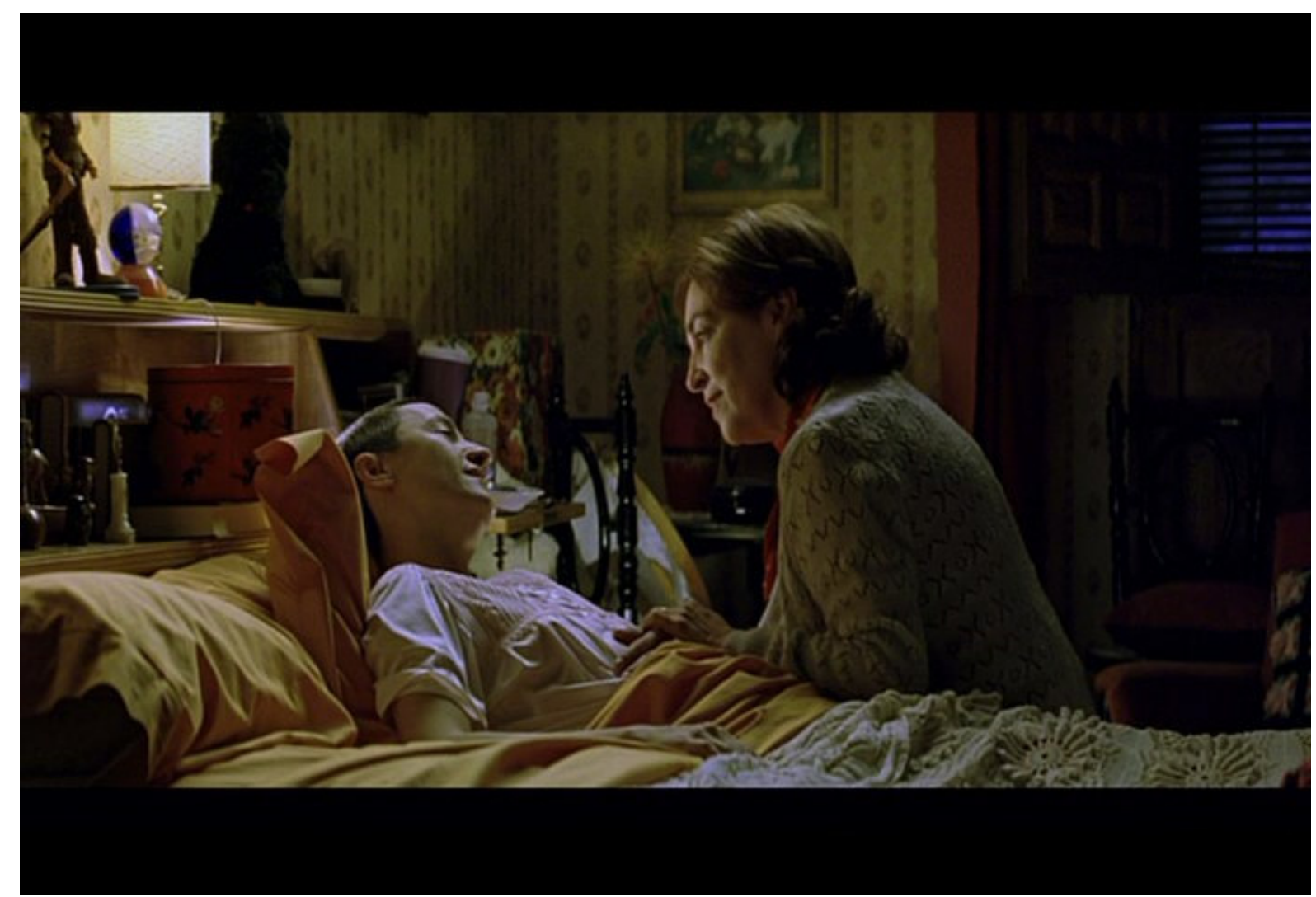

Figura 3 - Prática dos cuidados em "Volver” (ALMODÓVAR, 2006).

Fonte: Filme "Volver" (ALMODÓVAR, 2006).

Irene, nesse filme, tal como Manuela em “Tudo sobre minha mãe” (1999) e Benigno em "Fale com ela" (2002), desempenham amplos cuidados com sujeitos que, às vezes sim, mas muitas, não descendem deles. Ou seja, observando atentamente os pronunciamentos dos sujeitos femininos nos filmes analisados e o modo como eles se relacionavam com os demais, deparamo-nos com a posição do sujeito, ou seja: a posição de quem é mãe. Como se pode observar, eles não ocupam, necessariamente, a posição de mães biológicas àqueles que cuidam. Ao contrário, esses sujeitos são homens (Benigno) na função de enfermeiro; outros são mulheres (Manuela) que se propõem a cuidar de um bebê de seu ex-marido, que agora é travesti; outros, ainda, se escondem para se posicionar como cuidadora (Irene) da filha da mulher que assassinou. Contudo, todos esses sujeitos, apesar de conservarem suas características peculiares, cumprem no movimento do discurso a mesma função materna: os que praticam o cuidado aos seus assistidos. São sujeitos que demonstram amor e têm afeto àqueles de quem cuidam, sentimentos esses, que estão se fortalecendo nos novos modelos familiares.

Esses sujeitos nos parecem, personificam o ideal de mãe para Almodóvar e é por isso que ele as traz para o centro de suas narrativas. 
A seguir, traçaremos breves considerações sobre esta pesquisa.

\section{Considerações Finais}

O objetivo desta pesquisa foi de compreender a função do sujeito "feminino" nos filmes de Pedro Almodóvar, tendo em vista as seguintes questões: - o que eleger na análise de um acervo fílmico, uma vez que, em quase todos os textos desse diretor as mulheres se fazem presentes? - Como selecionar e relacionar nas análises as cenas e/ou as sequências fílmicas, neste universo de imagens em movimento? Para tanto, recorremos à teoria da análise do discurso de Michel Foucault (1995), em sua compressão sobre o "enunciado" e "formações discursivas".

No momento em que aplicamos os princípios de Foucault (1995) nas análises, foi possível observar um dos enunciados discursivos que se fizeram presentes nos três filmes analisados de Almodóvar, e esse diz respeito à: "prática dos cuidados realizados por sujeitos femininos aos seus familiares".

Neste universo do "feminino materno", foi possível recortar "famílias de Almodóvar", que nos sugeriam:

a) as famílias biológicas são compostas por três sujeitos: pai, mãe e descendente(s);

b) as famílias biológicas, em dado momento e por razões diversas, desestruturam-se, e buscam compor novas famílias, muitas vezes, sem laços de consanguinidade, mas assumindo suas identidades pessoais, relacionam-se devido à prática do cuidado;

Há predominância, nestes três filmes, de certa composição familiar matriarcal que prevalece no desfecho das histórias, Em "Tudo sobre minha mãe" (1999) observa-se que as mulheres (Manuela, Huma, Agrado, Irmã Rosa) constroem suas famílias, tanto na intimidade do lar, como também no camarim de um teatro. Em "Fale com ela" (2002), os locais em que as mulheres (Katerina e Alicia) estabelecem os laços familiares são construídos tanto nas aulas de dança como nos palcos de espetáculos. Em "Volver" (2006), a familiaridade advém da comunidade, que se fortalece nas refeições partilhadas entre as mulheres e seus momentos na cozinha.

InCID: R. Ci. Inf. e Doc., Ribeirão Preto, v. 2, n. 2, p. 54-66, jul./dez. 2011. 
Uma primeira conclusão que segue é que Almodóvar retrata em seus filmes que as famílias, nos dias atuais, ainda se constituem legalmente pelos laços de consanguinidade: pai, mãe e descendentes (consanguíneos ou adotados), mas elas também se constituem de modos ainda não legitimados, ou fora de padrões sociais previamente estabilizados.

Esses ambientes familiares, que centralizam as tramas de Pedro Almodóvar e a partir do qual os filmes são desenvolvidos, demonstram enunciativamente, a formação de um discurso, no caso: a de um discurso familiar da modernidade.

Tendo em vista que esta pesquisa pode vir a ser aplicada no campo da Ciência da Informação, uma vez que se trata de análise de acervos, no caso, fílmicos, o que se reconhece é que ainda não há bases de dados condizentes com a veiculação das análises, por esta via teórica do discurso. Relacionar imagens e palavras, por meio das descrições de acervos textuais, delimitando temas, e ao mesmo tempo, depurando conteúdos, contribuiria significativamente para que o leitor pudesse compor suas pesquisas, amparando-se, também, nas vozes presentes, no caso, do bibliotecário, arquivista, cientista da informação.

Fica o convite confiante aos leitores deste trabalho, para compor o coro destes estudos fecundos da análise do discursivo, no caso, foucaultiano, também no terreno da Ciência da Informação.

\section{Referências}

ARAÚJO, I. L. Foucault e a crítica do sujeito. 2 ed. Curitiba: Ed. da UFPR, 2008.

ARIÈS, P. História social da criança e da família. 2 ed. Rio de Janeiro: Guanabara Koogan, 1981.

FALE com ela. Direção: Pedro Almodóvar. Produção: Agustín Almodóvar. [Espanha]: El Deseo S. A.; Vía Digital; Antena 3 Televisión, 2002.

FISCHER, R. M. B. Foucault e a análise do discurso em educação. Cadernos de pesquisa, n.114, 2001. Disponível em: <http://www.scielo.br/pdf/cp/n114/a09n114.pdf>. Acesso em: 06.08. 2011.

FOUCAULT, M. A arqueologia do saber. 4 ed. Rio de Janeiro: Forense Universitária, 1995.

História da sexualidade 2: o uso dos prazeres. Rio de Janeiro: Graal, 1984.

A ordem do discurso: aula inaugural no Collège de France, pronunciada em 2 de

Dezembro de 1970. $5^{a}$ ed. São Paulo: Loyola, 1999a.

InCID: R. Ci. Inf. e Doc., Ribeirão Preto, v. 2, n. 2, p. 54-66, jul./dez. 2011. 
Microfísica do poder. Organização, Introdução e revisão técnica de_Roberto Machado. Rio de Janeiro: Graal, 1999 b.

. As palavras e as coisas: uma arqueologia das ciências humanas. São Paulo: Martins Fontes, 2000.

GASPAR, N. R. Foucault na linguagem cinematográfica. 2004. Tese (Doutorado em Linguística e Língua Portuguesa) - Universidade Estadual Paulista, Faculdade de Ciências e Letras, Araraquara.

GREGOLIN, M.R. O discurso, o sujeito e a história em A Arqueologia do Saber: Foucault e Pêcheux na Análise do Discurso - Diálogos e Duelos. Disponível em:

$<$ http://cibermidia.blogspot.com/2008/02/o-discurso-o-sujeito-e-histria-em.html>. Acesso em: 28.02. 2009.

GUILHAUMOU, J.; MALDIDIER, D. Efeitos do arquivo: a análise do discurso no lado da história. In: ORLANDI, E. P. (Org.). Gestos de leitura: da história no discurso. Campinas: Ed. UNICAMP, 1994. p. 163-183.

REPERTÓRIO CULTURAL. Disponível em: $<$ http://repertoriocultural.blogspot.com/2007_02_01_archive.html >. Acesso em: 06 agosto 2011>.

TRILHA FILMES. Disponível em: <http://www.trilhafilmes.com.br/noticia.php?id=01591>. Acesso em: 06 agosto 2011.

TUDO sobre minha mãe. Direção: Pedro Almodóvar. Produção: Agustín Almodóvar. [Espanha]: Renn Productions; El Deseo S. A.; France 2 Cinema, 1999.

VOLVER. Direção: Pedro Almodóvar. Produção: Agustín Almodóvar. [Espanha]: El Deseo S. A.; TVE; Canal+ España, 2006. 